\title{
Malignant melanoma in a Dog - A Case report
}

\author{
Podarala Veena, Soundararajan Kokila, Rayadurgam V. SureshKumar, \\ Palanisamy Sankar, Nekkanti Dhanalakshmi \\ College of veterinary science, \\ Sri Venkateshwara Veterinary University, Tirupati, AP, India \\ Corresponding author: S Kokila, email: gopika31@gmail.com \\ Received: 13-11-2011, Accepted: 16-12-2011, Published Online: 10-05-2012 \\ doi: $10.5455 /$ vetworld.2012.431-432
}

\section{To cite this article:}

Veena P, Kokila S, SureshKumar RV, Sankar P, Dhanalakshmi N, (2012) Malignant Melanoma in a Dog - A Case report, Vet World, 5(7):431-432, doi: 10.5455/vetworld.2012.431-432

\section{I ntroduction}

The oral cavity is the fourth most common site of neoplasia in dogs and malignant melanoma and squamous cell carcinoma are the most common type of tumors in this site [1]. In dogs, oral malignant melanomas most commonly arise from the gingiva, but also can originate from the palatine, labial or buccal mucosa [2]. Malignant melanomas are characteristically rapidly growing, locally invasive tumors that metastasize early in the course of the disease [3]. These tumors are widely recognized as a tumor of older dogs and are common in male than in female dogs. Melanomas were overrepresented in smaller breeds such as cocker spaniels and miniature poodles [4]. A case of surgical management of malignant melanoma in the hard palate of a dog was discussed here.

\section{Case History and Observations}

A five years old non descriptive breed dog was brought to the college clinics, Department of
Veterinary Surgery and Radiology, College of Veterinary Science, Sri Venkateswara Veterinary University, Tirupati with the history of growth over the hard palate in between the $3^{\text {rd }}$ premolar since 3 months. Slowly it had grown in size. The growth dark in color, firm and hard to touch (Figure-1). The animal showed excessive salivation, difficult in prehension and mastication was noticed.

Fine needle aspiration cytology revealed malignant cells appear as round or fusiform, with eccentric nuclei with dark black or brown color, small pigmented cytoplasm (Figure-2). Haematological, biochemical parameters were within the normal physiological limits. It was diagnosed as a tumor and was decided to perform surgery.

\section{Treatment}

The dog was premedicated with Atropine Sulphate@ $0.04 \mathrm{mg} / \mathrm{kg}$ body weight subcutaneously and sedated with Xylazine Hydrochloride $1.0 \mathrm{mg} / \mathrm{kg}$ body weight intra-muscularly. General anaesthesia was using Ketamine Hydrochloride @ $5.0 \mathrm{mg} / \mathrm{kg}$ body

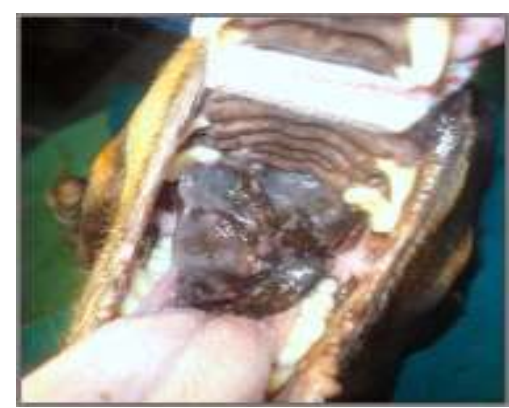

Figure-1. malignant cells dark in color firm and hard to touch

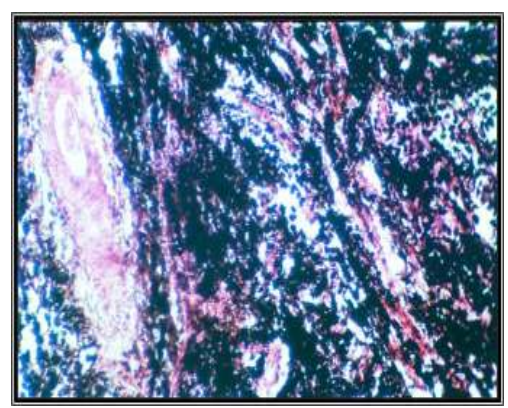

Figure-2. Malignant cells appear as round or fusiform, with eccentric nuclei with dark black or brown color, small pigmented cytoplasm

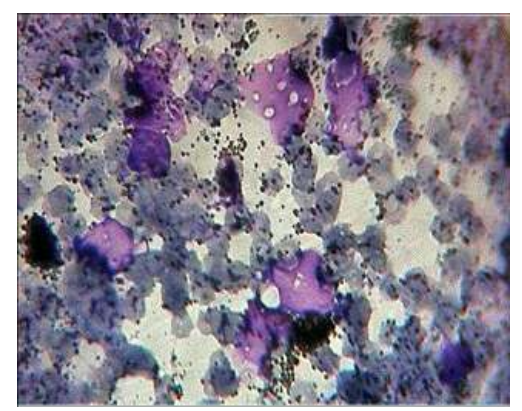

Figure-3. Varying amounts of melanin pigment

Veterinary World, Vol.5 No.7 July 2012 
weight and diazepam $0.3 \mathrm{mg} / \mathrm{kg}$ body weight intravenously. Tumor mass was excised after ligation of the base with catgut No.2. Post operatively Ceftriaxone was administered @ $20.0 \mathrm{mg} / \mathrm{kg}$ body weight intravenously and Meloxicam @ $0.50 \mathrm{mg} / \mathrm{kg}$ body weight subcutaneously for five days. Animal was maintained with intravenous fluids for 2 days. Tumour mass was subjected to histopathological examination. Histopathological examination revealed the growth consisted of cells that were oval or slightly elongated in shape. These cells were arranged in small bundles with moderate amounts of connective tissue in between. These cells contained varying amounts of melanin pigment in them (Figure-3). Each had nucleus and nucleolus. Mitotic activity was scanty. The growth was encapsulated with a thin fibrous capsule.

\section{Discussion}

Oral melanomas are locally aggressive and also have a high likelihood (80\%) of metastasis (spread) to other organs such as the regional lymph nodes and lungs. Malignant melanoma may invade to adjacent tissue and possibly bone. Early recognition of such tumors can lead to more successful attempts to remove the malignant mass. Bergman [5] stated that the established therapeutic approaches such as surgery, chemotherapy and fractional radiation therapy are not curative after metastasis in canine malignant melanoma. According to tumor size, location and type partial maxillectomy or mandibulectomy can be performed [6]. Radiotherapy was an effective palliative treatment for the primary tumor in dogs with oral malignant melanomas [1]. Carboplatin had activity against macroscopic spontaneously occurring malignant melanomas in $\operatorname{dogs}$ and should be considered as an adjunctive treatment for microscopic local or metastatic tumors [7]. Since melanoma is an antigenic tumor, immunotherapy can also be used [4].

\section{References}

1. Frazier SA, et al. (2008) Improved outcome in dogs with oral FSA treated with aggressive surgical resection with or without radiation therapy, in Proceedings of Vet Cancer Soc: 8.

2. Harvey H J, MacEwen EG, Braun D, et al. (1981) Prognostic criteria for dogs with oral melanoma $J \mathrm{Am}$ Vet MedAssoc $178: 580-82$.

3. Esplin DG. (2008) Survival of dogs following surgical excision of histologically well-differentiated melanocytic neoplasms of the mucous membranes of the lips and oral cavity. Vet Pathol 45(6):889-896.

4. Coyle VJ and Garrett LD (2009) Finding and treating oral melanoma, squamous cell carcinoma, and fibrosarcoma in dogs. Veterinary Medicine.

5. Bergman, P.J., Campus Palau,M.A., Mcknight, J A, Leibman N F, Craft D M, Leung C, Liao J, Rivierie I, Sadelain M, Hohenhaus A E, Gregor P, Houghton AN, Perales M A and Wolchok J D (2006). Development of a xenogenic DNA vaccine program for canine malignant melanoma at animal medical center. Vaccine, 24: 4582-85.

6. Wallace J and Matthiesen T (1991). Hemimaxillectomy for the Treatment of Oral Tumors in 69 Dogs. Veterinary Surgery 21(5), 337-341.

7. Rassnick KM, Ruslander DM,Cotter SM, Bruyette DS, Gamblin RM, Meleo KA and Moore AS (2001) Use of carboplatin for treatment of dogs with malignant melanoma: 27 cases (1989-2000) Journal of the American Veterinary Medical Association. 218(9), 1444-1448. 